
I $1.32 \%$.

1.3694 g. lost 0.1549 g. at $92^{\circ}$. Calc. for the above formula: 10.75\%. Found:

Preparation of the Compound $\left[\left(\mathrm{C}_{6} \mathrm{H}_{5}\right)_{3} \mathrm{COH}\right]_{4}\left[\mathrm{CCl}_{4}\right]_{3}$.-Triphenylcarbinol crystallizes from hot carbon tetrachloride on cooling in large, flat, square crystals. They begin to effloresce on being exposed to the air and soon become opaque. The compound was repeatedly prepared and analyzed on account of the fact that the analytical results did not agree with the simple formula that was anticipated from a consideration of the composition of the analogous compounds. The time during which the crystals were allowed to stand in the air was varied. The losses in weight in a series of analyses were as follows: $30.44,30.87,3$ r.06 and $30.77 \%$. The calculated loss for a compound containing one molecule of each constituent is $37.19 \%$ and for one containing two of the carbinol to one of carbon tetrachloride is $22.84 \%$. The calculated loss for a compound of the formula given above is $30.75 \%$.

Preparation of the Compound $\left[\left(\mathrm{C}_{6} \mathrm{H}_{5}\right)_{3} \mathrm{COH}\right]_{2}\left(\mathrm{CH}_{3}\right)_{2} \mathrm{CO}$.-Triphenylcarbinol crystallizes from acetone in large, transparent, prismatic crystals which effloresce slowly.

$0.6022 \mathrm{~g}$. lost $0.06 \mathrm{I} 3 \mathrm{~g}$. when heated to constant weight. Calc. for a compound of the above composition: $10.06 \%$. Found: $10.18 \%$.

Preparation of the Compound $\left(\mathrm{C}_{6} \mathrm{H}_{5}\right)_{8} \mathrm{CCl}$. CCl 4 . -Triphenylchloromethane crystallizes from carbon tetrachloride in small, lustrous crystals which do not effloresce rapidly in the air.

$0.5073 \mathrm{~g}$. lost $0.1444 \mathrm{~g}$. at $92^{\circ}$. Calc. for the above formula: $28.92 \%$. Found: $28.46 \%$.

Preparation of the Compound $\left[\left(\mathrm{C}_{6} \mathrm{H}_{5}\right)_{3} \mathrm{CCl}\right]_{2} \cdot\left(\mathrm{CH}_{3}\right)_{2} \mathrm{CO} .-\mathrm{A}$ compound of this composition was obtained by allowing a solution of triphenylchloromethane in acetone to evaporate spontaneously. The addition product is relatively stable.

$0.5916 \mathrm{~g}$. lost $0.0553 \mathrm{~g}$. at $92^{\circ}$. Calc. for the above formula: $9.43 \%$. Found: $9.35 \%$. NASHVILLE, TENNESSEE.

[Contribution from the Department of Research in PURe Chemistry, Melilon Institute, University of PitTsburgh.]

\title{
ON THE DETECTION AND DETERMINATION OF HALOGENS IN ORGANIC COMPOUNDS.
}

By I. Drogin and M. A. Rosanoff.

Received January 13, 1916.

Some years ago C. W. Bacon, ${ }^{1}$ at the instance of one of us (M. A. R.), undertook to test an apparently valuable method for determining halogens in organic compounds that had been recommended by Stepanoff in 1906.2

${ }^{1}$ Bacon, This Journal, 31, 49 (1909).

2 Stepanoff, Ber., 39, 4056 (I906). 
Stepanoff's method consisted in dissolving the given halogen compound in $98 \%$ alcohol and adding a certain excess of metallic sodium; later, diluting with water, distilling off the alcohol, acidifying with nitric acid and, finally, measuring the freed halogen acid by Volhard's method. Bacon followed Stepanoff's directions scrupulously, yet the results were unsatisfactory. Then, in view of the great simplicity of Stepanoff's method and its obvious advantages over the generally used method of Carius, Bacon undertook to improve Stepanoff's directions, and after a certain amount of experimenting believed to have succeeded in developing Stepanoff's principle into a universally reliable analytical method. In his paper, Bacon reports a series of successful analyses of some decidedly refractory compounds, including ten consecutive analyses of hexachlorobenzene. The problem thus appeared to be solved.

'l'wo years later Stepanof's method was independently investigated by C. H. Maryott.' At the suggestion of Professor Van Name, Maryott substituted potassium in place of the sodium used by Stepanoff, and analyzed chlorobenzene, bromobenzene, hexachlorobenzene, and p-chloroaniline, with sufficiently good results. Maryott claims greater rapidity for his method by comparison with the sodium method as recommended by Bacon.

Bacon's directions, on the other hand, were investigated by Walker and $\mathrm{MCRae},{ }^{2}$ but with unsatisfactory results:

"With Bacon's method," they say, "about forty trials were made [in the case of bromobenzene ], all of the results being low, and in no case were duplicates obtained which agreed, which showed that the reduction was incomplete and irregular." Walker and McRae were "forced to conclude, therefore, that this method is not of general applicability, and especially cannot be used with difficultly reducible substances."

Most of the results obtained by Walket and McRae were only one or two per cent. low. Bacon himself, as already stated, had obtained a series of very good results inceed. It appeared possible, therefore, that Stepanoff's principle might yet be developed into a desirable analytical method by an appropriate modification of Bacon's procedure. And when, early in 1915, another investigation in which the present authors were engaged had to be temporarily interrupted, it was decided to re-investigate the halogen problem and make a new attempt to render fruitful the principle employed by Stepanoff.

A series of trials according to the directions recommended by Bacon soon convinced us that Walker and McRae were right, and that those directions were really somewhat imperfect. Another series of trials, in which we followed the directions given by Maryott, using $m$-bromobenzoic acid, yielded still poorer results, and even when the amount of potassium used was four or five times that specified by Maryott, our

\footnotetext{
${ }^{1}$ Maryott, Am. J. Sci., 30, 378 (1910); Chem. News, 103, I (1911).

2 This Journal, 33, 598 (I911).
} 
figures were still several per cent. below the theoretical percentage. Possibly Maryott may have neglected to mention some essential detail of manipulation.

We then undertook a systematic series of experiments, gradually modifying Bacon's method in its several steps; and at last our efforts were, we think, successful. We found that increasing Bacon's amount of sodium by $10 \%$ and, at a later stage, carrying out the Volhard halogen determination with all necessary care, led to uniformly excellent results in all cases without exception. This, we believe, is fully enough demonstrated below by the results of sixty-four consecutive analyses of eleven substances belonging to different classes. In order to positively insure success in the use of the method by others, the directions will be stated in great detail.

\section{Directions.}

The required reagents are: (I) absolute alcohol; (2) metallic sodium; (3) pure nitric acid; (4) a $N / 15$ solution of silver nitrate; (5) a $N / 15$ solution of ammonium thiocyanate; and (6) a solution of ferric ammonium alum.

Remarks Concerning the Reagents.-Ordinary absolute alcohol should be redistilled from metallic sodium, about lo g. of sodium being used per liter of alcohol. As a precaution against any possible oxidation of the alcohol, the distillation may be carried out in a slow stream of dry hydrogen. The sodium should be carefully tested for the presence of halogens. The best commercial sodium will be found to be sufficiently pure. If only a less pure metal is available, a determination of its chlorine content must be carried out on a sample of at least io g., and subsequently the error due to this source corrected. ${ }^{1}$ The oxide film on the surface of the metal should be removed, and the bright pieces weighed and kept for use under kerosene oil. The nitric acid and the water used should, of course, be halogen free; the reagent should contain one part of the concentrated acid to three parts of water. The $N / 1_{5}$ solution of silver nitrate may be made up by dissolving II.326 g. of the dry salt in water and diluting to one liter. Naturally, the exact strength of the solution must be determined either gravimetrically, or volumetrically by titration against a hydrochloric acid of precisely known strength. ${ }^{2}$ The ammonium thiocyanate reagent may be made up by dissolving $5.075 \mathrm{~g}$. of the pure dry salt in water and diluting to one liter. The exact strength of the solution is determined by titration against the above silver nitrate solution. The ferric salt indicator is made up by preparing a solution of ferric ammonium alum as nearly saturated as possible, and adding concentrated nitric acid until the original red of the solution has turned to straw-yellow.

1 The sample of sodium used by ourselves required a correction of from 0.1 to 0.2 in the percentage of halogen in the compounds.

${ }^{2}$ See Hulett and Bonner, This Journal, 3 1, 390 (1909). 
Amounts of Alcohol and Sodium Required.-A large number of experiments have demonstrated that the following relative quantities of alcohol and sodium are necessary and sufficient for the complete extraction of the halogens from apparently any organic combination. If $W$ denotes the weight of substance taken (between 0.2 and $0.3 \mathrm{~g}$.), and if the halogen in the given compound is chlorine, then the number of cubic centimeters of alcohol in which the substance is to be dissolved, should be $156 \mathrm{~W}$; the number of grams of sodium to be used then is $21.5 \mathrm{~W}$. If the given compound contains bromine, then $68 \mathrm{~W}$ ec. of alcohol and $9.4 \mathrm{~W}$ g. of sodium should be used. If the compound contains iodine, then $44 \mathrm{~W}$ cc. of alcohol and $6 . \mathrm{r} \mathrm{W}$ g. of sodium should be used.

Principal Operation.-From 0.2 to $0.3 \mathrm{~g}$. of the substance to be analyzed is introduced into a dry $\mathbf{K}$ jeldahl flask of $300 \mathrm{cc}$. capacity, the required amount of absolute alcohol is added, and the flask attached to a Liebig reflux condenser (the constricted end of the inner tube of the condenser is best cut off). The contents of the flask are now warmed with a burner flame placed under an asbestos gauze; when the solid has dissolved, the flame is turned out, and the gradual introduction of the sodium is begun. Small pieces of the metal are removed from the kerosene in which they have been kept, rapidly dried, with filter paper, and rolled out into little rods, which are dropped into the solution through the condenser. At no time should there be more than, say, three pieces of undissolved sodium together in the flask. The introduction of the sodium should take altogether about thirty minutes, and during at least the second half of the time the dissolution of the sodium should be aided by a small flame under the flask. After all the sodium has been introduced the solution should be allowed to boil gently for a full hour, during which it should be shaken three or four times to help dissolve the metal. Sometimes even this does not suffice to dissolve the last particles of metal; but a small undissolved remnant is harmless. Now, after cooling, the contents of the flask are diluted through the condenser with water, I cc. at a time being added at first, as long as vigorous action ensues. The total volume of the diluted solution should be about $250 \mathrm{cc}$. Carbonization, which at times occurs during dilution, is harmless. Next the solution, while kept cool with tap-water, is acidified with the I to 3 nitric acid reagent (the addition of nitric acid generally causes considerable reduction of the reddish color of the diluted alkaline solntion) ${ }^{1}$

On transferring the acidified contents of the Kjeldahl flask into a large beaker, a measured amount of silver nitrate solution is added, sufficient to precipitate the entire halogen present and about $3^{-4} \mathrm{cc}$. in excess. The

I If the halogen involved is iodine, the alkaline solution should be acidified more slowly and with much greater caution; it should be thoroughly cooled with ice, and a much more dilute nitric acid employed. 
precipitate is filtered off, ${ }^{1}$ the filtrate being allowed to run into a porcelain dish of about one liter capacity. To the filtrate are added ro cc. (no less) of the ferric indicator, and then ammonium thiocyanate is run in, to the apResurrs.

I. Chlorobenzene, $\mathrm{C}_{6} \mathrm{H}_{6} \mathrm{Cl}$.

Theory, $31.52 \%$ chlorine. Chlorine found. Difference. Per cent.

$\begin{array}{ll}31.34 & -0.18 \\ 31.33 & -0.17 \\ 31.51 & -0.01 \\ 31.38 & -0.14 \\ 31.31 & -0.21\end{array}$

IV. Benzene Hexachloride $\mathrm{C}_{6} \mathrm{H}_{6} \mathrm{Cl}_{6}$.

Theory, $73.16 \%$ chlorine. Theory, $22.66 \%$ chlorine. Chlorine found. Difference. Per cent.

$\begin{array}{ll}73.22 & +0.06 \\ 73.21 & +0.05 \\ 73.26 & +0.10 \\ 73.08 & +0.08 \\ 73.23 & +0.07\end{array}$

\section{Bromobenzene,} $\mathrm{C}_{6} \mathrm{H}_{5} \mathrm{Br}$.

Theory, $50.92 \%$ bromine. Bromine found. Difference. Per cent.

$$
\begin{aligned}
& 50.78 \\
& 50.79 \\
& 50.75 \\
& 50.82 \\
& 50.86 \\
& 50.84
\end{aligned}
$$

$$
\begin{array}{cr}
\text { Per cent. } & \begin{array}{r}
\text { Difference. } \\
\text { Per cent. }
\end{array} \\
22.66 & 0.00 \\
22.63 & -0.03 \\
22.54 & -0.12 \\
22.58 & -0.08 \\
22.61 & -0.05 \\
22.60 & -0.06
\end{array}
$$

III. Hexachlorobenzene, $\mathrm{C}_{6} \mathrm{Cl}_{8}$.

Theory, $74.71 \%$ chlorine.

Chlorine found. Difference. Per cent. Per cent.
74.59
$\longrightarrow .12$
74.61
$\longrightarrow$. ro
74.61
$\rightarrow .10$
74.60
$\multimap .11$
74.59
$-0.12$
74.61
$\longrightarrow .10$

VI. $p$-Chlorobenzoic Acid, $\mathrm{C}_{8} \mathrm{H}_{1} \mathrm{ClCO}_{2} \mathrm{H}$.

Theory, $22.66 \%$ chlorine.

Chlorine found. Diff erence.
Per cent.

VII. $m$-Bromobenzoic Acid, VIII. p-Bromobenzoic Acid,

$\mathrm{C}_{6} \mathrm{H}_{4} \mathrm{BrCO}_{2} \mathrm{H}$.

Theory, $39.77 \%$ bromine. Theory, $39.77 \%$ bromine. Bromine found. Difference.
Per cent.

$\begin{array}{ll}39.71 & -0.06 \\ 39.71 & -0.06 \\ 39.67 & -0.10 \\ 39.75 & -0.02 \\ 39.68 & -0.09 \\ 39.64 & -0.13\end{array}$

X. $\alpha$-Bromonaphthalene, $\mathrm{C}_{10} \mathrm{H}_{7} \mathrm{Br}$.

Theory, $38.61 \%$ bromine. Bromine found. Difference.

$$
\text { Per cent. }
$$

38.60

38.60

38.47

38.51

38.53

38.65
Bromine found. Difference. Per cent. Per cent.

$$
\begin{aligned}
& 39.67 \\
& 39.66 \\
& 39.71 \\
& 39.68 \\
& 39.64 \\
& 39.78
\end{aligned}
$$

\section{Per cent.}

$$
\longrightarrow .01
$$$$
-0.01
$$$$
\longrightarrow .14
$$$$
-0.10
$$$$
-0.08
$$$$
+0.04
$$

$\multimap .10$

$\longrightarrow$ - I I

$-0.06$

$-0.09$

$-0.13$

$+0.01$

$$
\begin{array}{ll}
22.60 & -0.06 \\
22.60 & -0.06 \\
22.67 & +0.01 \\
22.54 & -0.12 \\
22.62 & -0.04 \\
22.63 & -0.03
\end{array}
$$

IX. Benzyl Chloride, $\mathrm{C}_{6} \mathrm{H}_{3} \mathrm{CH}_{2} \mathrm{Cl}$.

Theory, $28.03 \%$ chlorine.

Chlorine found. Difference. Per cent. Per cent.
27.94
$\longrightarrow .09$
$27.8 \mathrm{I}$
$\longrightarrow .22$
27.95
$-0.08$
28. 10
$+0.07$
$27 \cdot 96$
$-0.07$
27.96
$-0.07$

XI. Iodoform, $\mathrm{CHI}_{3}$.

$\begin{array}{cc}\text { Theory, } 96.70 \% \text { iodine. } \\ \text { Iodine found. } \\ \begin{array}{c}\text { Der cent. } \\ \text { Per cence. }\end{array} \\ 96.39 & -0.31 \\ 96.62 & -0.08 \\ 96.49 & -0.21 \\ 96.57 & -0.13 \\ 96.44 & -0.26 \\ 96.52 & -0.18\end{array}$

${ }^{1}$ See Rasanoff and Hill, This JouRNAL, 29, 269 (1907). In the analyses reported in the present paper the silver halide precipitates were invariably filtered off, bromide and iodide as well as chloride. 
pearance of a faint but distinctly perceptible pink color. An additional two drops of the thiocyanate solution should make the color quite strong and prove that the true end point had been attained.

The Handling of Liquid Substances.--In analyzing liquids we used a glass tube $30 \mathrm{~mm}$. long and $6 \mathrm{~mm}$. in internal diameter, one end of the tube being sealed with a thickness of $3-4 \mathrm{~mm}$. of paraffin wax. During the weighing, the tubelet was closed with a cork, which was removed immediately before tubelet and substance were introduced into the alcohol in the Kjeldahl flask.

\title{
A Qualitative Test for Halogen.
}

Our uniform success with the method described above suggested its use also as a qualitative test for halogens in organic compounds. A series of trials, using p-chlorobenzoic acid, o-chlorophenol, bromobenzene, bromonaphthalene, and iodoform, showed that the merest traces of halogen can be positively detected by the following simple procedure:

A few milligrams of the given substance are dissolved in one cubic centimeter of pure absolute alcohol; a few small bright pieces of pure metallic sodium are thrown into the solution, one at a time, with gentle warming toward the end; on cooling, the solution is acidified with I cc. of dilute nitric acid ( 3 parts of water to I part of acid), and filtered, if necessary; after testing the acidity of the solution, Io drops of an approximately $N / 15$ silver nitrate solution are added. A parallel blank test will of course make the result surer.

In this way, for instance, we plainly detected chlorine in I drop of a liquid produced by adding a single drop of carbon tetrachloride to $30 \mathrm{cc}$, of benzene. In the same case the Beilstein test gave a doubtful result.

Pitrseura. Pa.

\section{A POSSIBLE SOURCE OF ERROR IN COLORIMETER OBSERVA- TIONS.}

\author{
BV J. H. LONG. \\ Received December 27, 1915.
}

Something over a year ago, in a series of observations just started, and in which a Duboscq colorimeter was employed, I noticed a marked variation from an anticipated result. The instrument had been in use for years and had always shown a correct zero point when the bottom of the glass cell and the plunger prism were brought in contact.

The standard colored liquid was in the left-hand cell and the one under investigation in the right. The observed column lengths were about 80 and roo. (The exact values are not recalled, but these are given to illustrate the situation.) The concentration of the investigated liquid was therefore about $80 \%$ of the other. On reversing the liquids, that is, putting the standard in the right-hand cell and adjusting the plunger to 